\title{
Analysis and Development of A Robust Fuel for Gas-Cooled Fast Reactors
}

\author{
FINAL REPORT \\ 1 January 2006 to 31 December 2009 \\ DOE Award Number: DE-FG02-06ER46270 \\ Grant Number: ER46270 \\ Office of Basic Energy Science \\ U.S Department of Energy \\ SC-22.2/Germantown Building \\ 1000 Independence Avenue, SW \\ Washington, DC 20585-1290 \\ Under Program \\ Experimental Program to Stimulate Competitive Research (EPSCoR), \\ Building EPSCoR-State/National Laboratory Partnerships
}

\author{
Principal Investigator: \\ Travis W. Knight, Ph.D. \\ University of South Carolina \\ Department of Mechanical Engineering \\ 300 Main Street \\ Columbia, SC 29208 \\ Tel: (803)777-1465 \\ FAX: (803)777-0106 \\ twknight@sc.edu
}

\section{Collaborating Lab Partner:}

Thad M. Adams, Ph.D.

Savannah River National Laboratory

Materials Applications and Process Technology Group 


\section{TABLE OF CONTENTS}

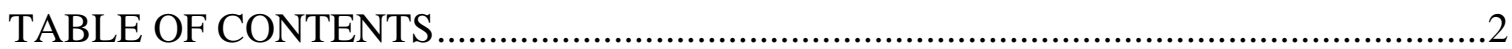

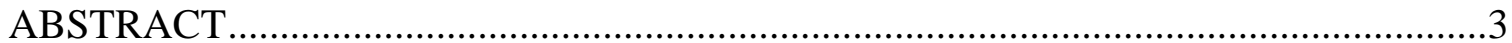

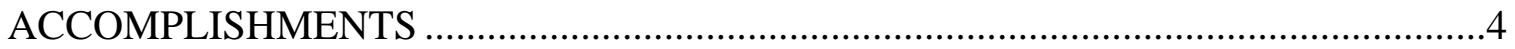

PAPERS PUBLISHED ......................................................................................

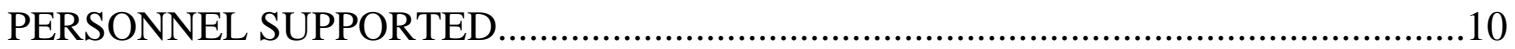

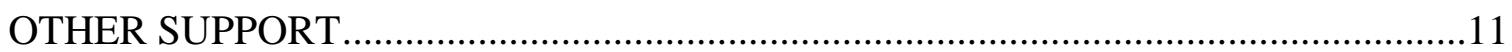

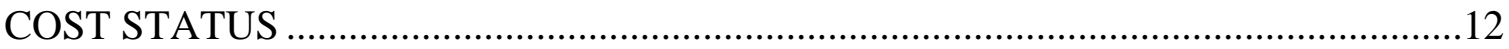




\begin{abstract}
The focus of this effort was on the development of an advanced fuel for gas-cooled fast reactor (GFR) applications. This composite design is based on carbide fuel kernels dispersed in a $\mathrm{ZrC}$ matrix. The choice of $\mathrm{ZrC}$ is based on its high temperature properties and good thermal conductivity and improved retention of fission products to temperatures beyond that of traditional SiC based coated particle fuels. A key component of this study was the development and understanding of advanced fabrication techniques for GFR fuels that have potential to reduce minor actinide (MA) losses during fabrication owing to their higher vapor pressures and greater volatility.

The major accomplishments of this work were the study of combustion synthesis methods for fabrication of the ZrC matrix, fabrication of high density UC electrodes for use in the rotating electrode process, production of UC particles by rotating electrode method, integration of UC kernels in the ZrC matrix, and the full characterization of each component.

Major accomplishments in the near-term have been the greater characterization of the UC kernels produced by the rotating electrode method and their condition following the integration in the composite ( $\mathrm{ZrC}$ matrix) following the short time but high temperature combustion synthesis process.

This work has generated four journal publications, one conference proceeding paper, and one additional journal paper submitted for publication (under review).

The greater significance of the work can be understood in that it achieved an objective of the DOE Generation IV (GenIV) roadmap for GFR Fuel-namely the demonstration of a composite carbide fuel with $30 \%$ volume fuel. This near-term accomplishment is even more significant given the expected or possible time frame for implementation of the GFR in the years 2030 -2050 or beyond.
\end{abstract}




\section{ACCOMPLISHMENTS}

o Demonstrated combustion synthesis study of $\mathrm{ZrC}$ matrix measuring the adiabatic and ignition temperatures. (see Papers Published \#4)

ZrC compacts were produced by the direct reaction of zirconium and graphite powders. The reaction is highly exothermic and is also classified as self-heating high temperature synthesis (SHS) or combustion synthesis (CS). This method avoids issues of large amounts of oxygen impurities which result from carbothermal reduction of the oxide with graphite but handling under an inert atmosphere in a glovebox and vacuum chamber is required due to the pyrophoric nature of zirconium powders. Fine powders of zirconium and graphite thoroughly mixed and pressed to form green bodies of desired shapes are heated to a particular temperature known as the ignition temperature $\left(T_{i g}\right)$ within a short period of time. Beyond this point, a combustion wave starts and propagates through the compact converting the reactant mixture into ZrC. External heating was accomplished by induction heating with a graphite susceptor in which the compact was placed. An ignition temperature of $1200^{\circ} \mathrm{C}$ and an adiabatic temperature varying from 2422 to $2528^{\circ} \mathrm{C}$ were measured. The adiabatic temperature is significant in that it will determine the degree of compact sintering achievable simply by the CS process. Pressure was applied to the compacts using a graphite punch to give between 1.4 and $5.2 \mathrm{MPa}$ additional driving force for sintering which is tantamount to hot pressing. Using this method compacts with as high as $85 \%$ TD were achieved. Xray diffraction confirmed that the reactants were converted to the carbide and that only the monocarbide $\mathrm{ZrC}$ was present. A parametric study was conducted to understand the impact of varying process conditions such as powder size, mixing time, etc. on compact quality.

o Demonstrated fabrication of UC electrodes for production of particles by rotating electrode mechanism. (see Papers Published \#3)

The UC electrode fabrication utilized uranium metal that was hydrided to form a powder for mixing with the graphite. This was done to avoid or reduce as much as possible contamination of the compact with oxygen. This study was performed to produce UC compacts that would stand up to the thermal and mechanical stresses of the rotating electrode device for UC particle production. First, results of combustion synthesis experiments showed that compacts produced without additional solid-state sintering beyond the brief combustion synthesis (reaction sintering) process were too porous and brittle to have sufficient strength for the rotating electrode device. Therefore, extended sintering of the compacts was sought. Still, the lowest sintering temperature and shortest time was sought to enable inclusion of minor actinides in the future intended fuel form for recycling of spent nuclear fuel in the GFR. Three sintering temperatures were tested, $1521^{\circ} \mathrm{C}, 1779^{\circ} \mathrm{C}$, and $1929^{\circ} \mathrm{C}$. The first is likely considered the upper limit for processing of metal fuels containing minor actinides but this might be higher for chemically combined forms such as carbides. The other two temperatures represent points above and below two-thirds the melting point of UC which is traditionally the minimum temperature required for solid-state sintering. Results of these tests showed 
that compacts formed by additional sintering at $1929^{\circ} \mathrm{C}$ for two hours produced compacts with densities greater than $87 \%$ TD and low open porosity (less than 3\%) as shown in Figure 1.

o Fabrication and characterization of UC microspheres by rotating electrode method. (see Papers Published, \#2,\#6)

Using the UC electrodes produced at $1929^{\circ} \mathrm{C}$, particles in the range of 300 to $1000 \mu \mathrm{m}$ were fabricated by the rotating electrode method (REM) (see Figure 2). Attempts with electrodes produced at the other temperatures discussed earlier tended to fragment and the particles produced were very small and irregular. This was attributed to non-uniform resistance and induced thermal stresses leading to fragmentation of these highly porous electrodes. Characterization of the UC microspheres revealed a very dense ( $>98 \%$ TD) highly dendritic microstructure (see Figure 3).

o Production of composite fuel form of UC particles embedded in a $\mathrm{ZrC}$ matrix. (see Papers Published, \#5,\#6)

Composite fabrication with UC particles in the ZrC matrix was conducted (see Figure 4). These tests were done to establish the effect of a large volume fraction of non-reacting material (prefabricated UC particles) on the combustion synthesis of the $\mathrm{ZrC}$ matrix. Also, the effect of the high temperature combustion wave on the integrity of the UC particles was sought. Microanalysis of compacts showed minor cracking of the kernels but their integrity in the $\mathrm{ZrC}$ matrix was maintained. Composite samples were further characterized in later periods as described below.

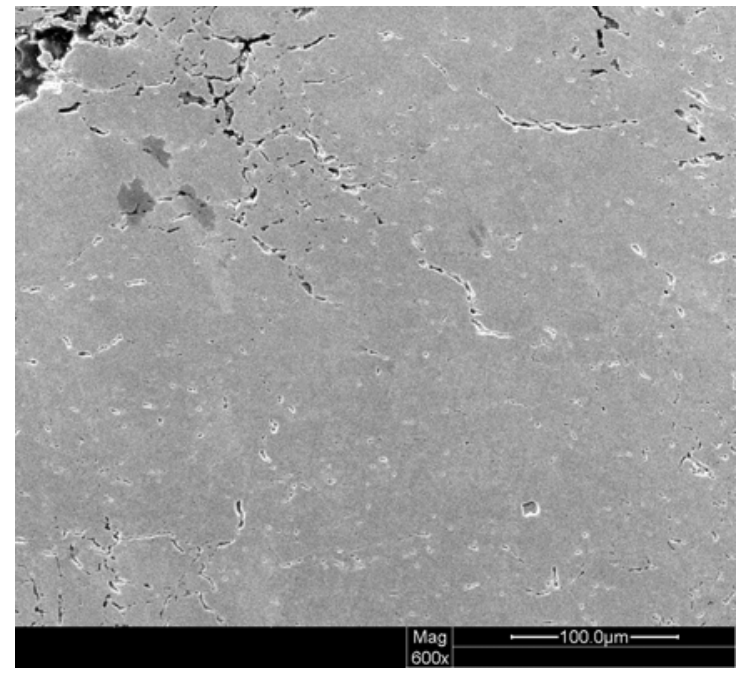

Figure 1. Relatively dense microstructure of UC compacts produced at $1929^{\circ} \mathrm{C}$ for two hours.

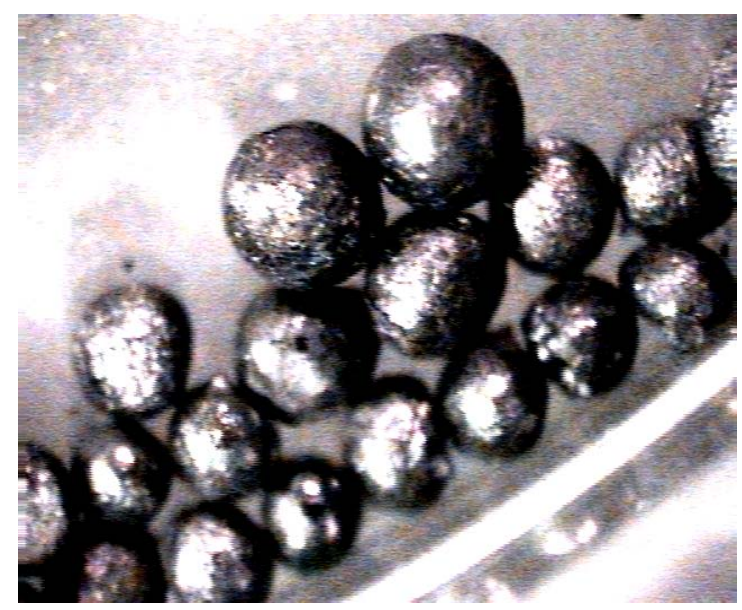

Figure 2. UC particles produced by the rotating electrode method. 


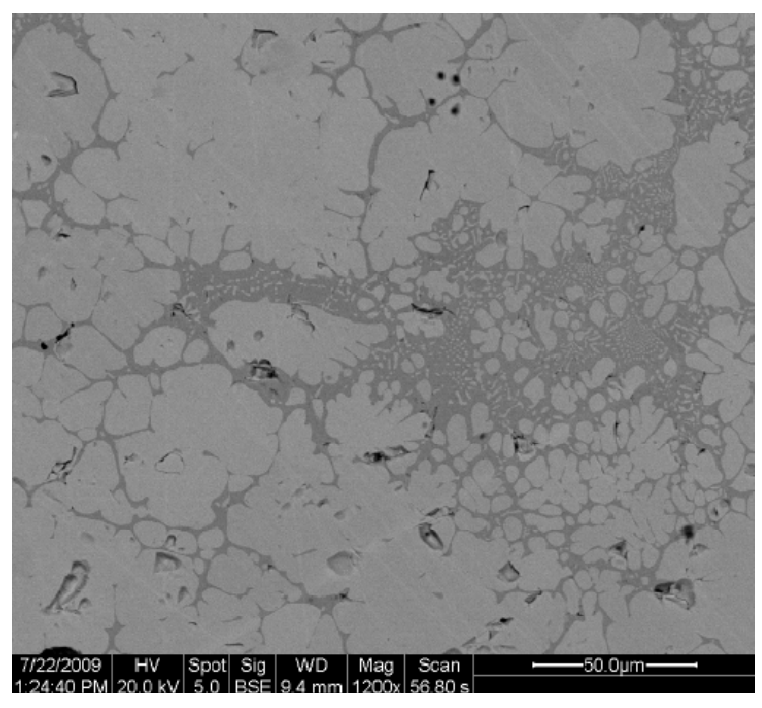

Figure 3. Microstructure of UC particles produced by rotating electrode mechanism.

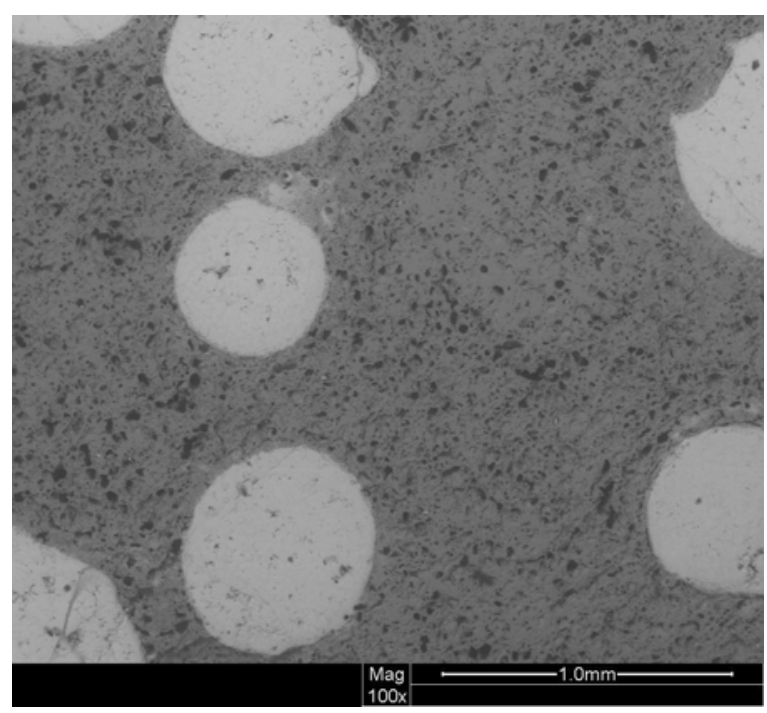

Figure 4. Composite compacts of UC particles dispersed in a $\mathrm{ZrC}$ matrix.

A series of experiments were conducted in the more recent period focused on characterization of the UC kernels fabricated by REM and their condition following integration into the composite ZrC-UC fuel (Geathers, 2009). To better understand the as fabricated conditions of the microspheres, the bulk carbon content was sought. While initial stock materials were prepared with uranium and carbon in stoichiometric proportion $(\mathrm{C} / \mathrm{U}=1)$, post-fabrication electron microanalysis indicated the material's composition was of a dendritic microstructure (Figure 3), and a carbon rich stoichiometry (C/U atomic ratio greater than one).

To determine the kernel's bulk carbon content, the UC samples were analyzed using a Netzsch Simultaneous Thermal Analyzer (STA) 409 CD to measure weight change in an oxidizing atmosphere. During oxidation of the carbide, the carbide carbon is first ignited, followed by free carbon. This reaction scheme is supported by the underlying thermodynamics by its comparatively low Gibbs free energy of formation compared to other potential products formed by the system (Figure 5). The Richardson-Ellingham diagram shows that the reaction of oxygen with UC is thermodynamically preferential than to that of carbon oxidation due to its more exothermic formation energy relative to free carbon. Hence oxidation of the carbide has a much higher affinity for reaction, as substantiated by the lower formation energies of both $\mathrm{CO}$ and $\mathrm{CO}_{2}$.

Nine total samples were analyzed with weights between 20.5 and $30.1 \mathrm{mg}$. An increase in weight followed by a small loss in weight around $550^{\circ} \mathrm{C}$. The thermobalance readout showed significant weight gain in the $300-500^{\circ} \mathrm{C}$ range, suggesting the oxidation of carbide carbon, followed by a rapid weight loss, assumed to be from the ignition of free carbon after all carbide carbon had been oxidized. An example output given by the TGA is given in Figure 6, showing weight change, temperature, and gas mass flow rate all as functions of time. 
Combining thermodynamic theory with the results exhibited, it was assumed with good reason that oxidation of the carbide carbon happened before that of free carbon. One can see in Figure 6 a major weight increase near $400^{\circ} \mathrm{C}$. This is most likely carbide carbon being oxidized, as substantiated by the literature and the underlying thermodynamics of the possible reactions that could be exhibited in this reaction space. As the temperature approaches $500^{\circ} \mathrm{C}$, weight loss is exhibited by the free carbon in the sample, before finally losing slightly more weight and settling to an equilibrium weight at low temperatures. Buoyancy effects from the gases used in the experiment may also have contributed to the change in weight at low temperatures, but were corrected for prior to measurement, so these factors are believed to be of small impact to the measurements.

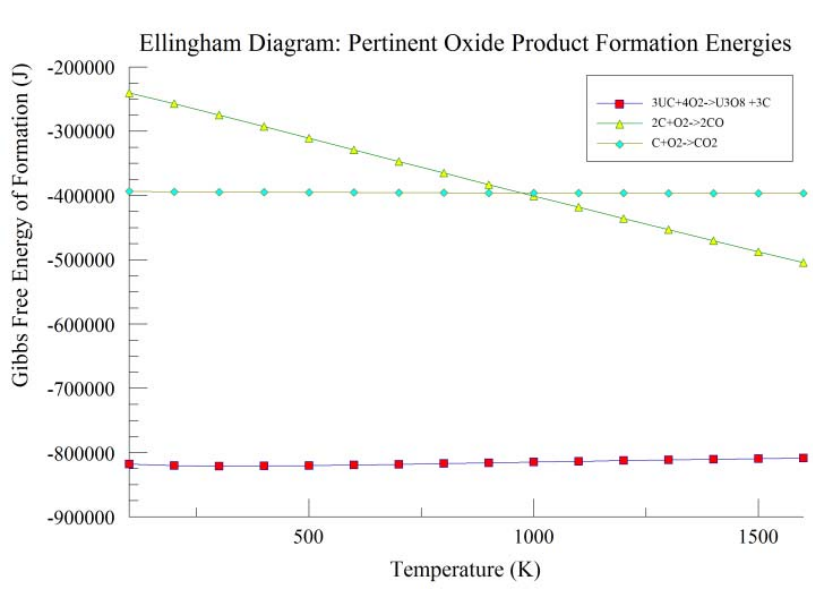

Figure 5. Richardson Ellingham Diagram showing preferential oxidation of carbide bound carbon over free carbon for all temperatures involved. Notable change can be seen in carbon-oxygen gas formation with temperature, but this does not hinder results (created using FACTSAGE 2006).

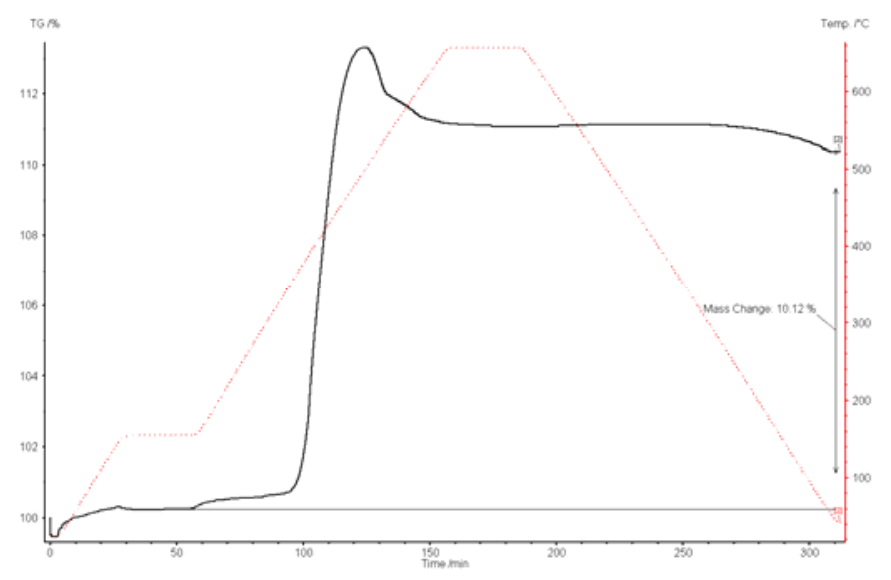

Figure 6. TGA sample profile output

Hence, the sequence of events is as follows: Initially carbide carbon is oxidized, causing an increase in weight of the sample. After this oxidation, the remaining free carbon in the sample is oxidized, and the carbon leaves the sample as $\mathrm{CO}$ or $\mathrm{CO}_{2}$. After this, the weight loss becomes less significant, eventually settling to an equilibrium weight post-cooling at near room temperatures.

The oxidation experiments showed the samples to be of moderately carbon rich proportions. By back calculating based on weight change, the average carbon to uranium atomic ratio was determined to be 1.23 for the kernels and agrees with the analysis of the different phases of the dendritic microstructure of kernels noted earlier. In conclusion, the samples were found to be carbon rich as originally hypothesized. The consistency of the data gives confidence in these measurements. Agreement with similar research found in the literature substantiates that the experimental conditions utilized for the carbon determination were accurate. Future fabrication conditions (such as the starting carbon to 
uranium ratio) would need to be altered to accommodate the pickup of carbon from the graphite dies during the fabrication of the UC electrodes and the possible loss of some uranium during the kernel fabrication by REM.

\section{References}

Geathers, Jerome J., Characterization of uranium carbide microspheres in an inert matrix zirconium carbide matrix for gas fast reactors, Thesis, University of South Carolina, December 2009

FactSage Thermochemical Software and Databases Bale C.W., Chartrand P., Degterov S.A., Ben Mahfoud R., Melançon J., Pelton A.D., Eriksson G., Hack K., Petersen S., 2006 


\section{PAPERS PUBLISHED}

1. Vasudevamurthy, G., T. W. Knight, E. Roberts, and T. Adams, "Production of ZrC matrix for use in Gas Fast Reactor composite fuels", Proceedings of Global 2007 Advanced Nuclear Fuel Cycles and Systems, September 9-13, 2007

2. Vasudevamurthy, G. and T. W. Knight, "Effect of system parameters on size distribution of 304 Stainless Steel particles produced by Electrical Discharge Mechanism”, Materials Letters, 61, 27, November 2007

3. Vasudevamurthy, G., T. W. Knight, "Production of High Density Uranium Carbide compacts for use in Composite Nuclear Fuels”, Nuclear Technology, 163, 2, August 2008, pp. 321-327

4. Vasudevamurthy, G., T. W. Knight, E. Roberts, and T. Adams, "Laboratory Production of Zirconium Carbide Compacts for Use in Composite Nuclear Fuels”, Journal of Nuclear Materials, 347, 1-2, 2008, pp. 241-247

5. Degange, J., T. W. Knight, and E. Roberts, "Bulk Composition Carbon Determination in Uranium Carbide Microspheres by Thermogravimetry,” Journal of Nuclear Materials, submitted December 2009

6. Vasudevamurthy, G., T. W. Knight, T. M. Adams, and E. Roberts, "Production and Characterization of ZrC-UC Inert Matrix Composite Fuel for Gas Fast Reactors”, Nuclear Technology, accepted for publication 


\section{PERSONNEL SUPPORTED}

\begin{tabular}{|l|l|l|l|}
\hline \multicolumn{1}{|c|}{ Name } & \multicolumn{1}{c|}{ Role/Title } & \multicolumn{1}{c|}{ Support } & \multicolumn{1}{c|}{ Percentage } \\
\hline Travis W. Knight & Assistant Professor & Partial & $16 \%$ \\
\hline Elwyn Roberts & Adjunct Professor & Partial & $30 \%$ \\
\hline $\begin{array}{l}\text { Gokul } \\
\text { Vasudevamurthy }\end{array}$ & Graduate Student & Full & $100 \%$ \\
\hline Jerome Geathers & Graduate Student & Full & $100 \%$ \\
\hline Sergiy Y. Lobach & Graduate Student & Full & $100 \%$ \\
\hline Patrick McNeil & Undergraduate Student & Partial & n/a \\
\hline Matthew Presson & Undergraduate Student & Partial & n/a \\
\hline Robert Kalgren & Undergraduate Student & Partial & n/a \\
\hline
\end{tabular}




\section{OTHER SUPPORT}

o Department of Energy-GNEP, "Laboratory Enhancements for Advanced Nuclear Fuel Development Related to GNEP,” 2007 to 2008, one half-time graduate student.

This grant will allow the purchase of a helium pycnometer to accurately measure density of small quantities of different components of coated particle fuels. A device will also be purchased to measure particle size. It also will build a test stand for production of microspheres by sol gel techniques. The goal of this work is related to mixed oxide and advanced TRISO coated particle fuels for high temperature reactors however the first two pieces of equipment might find use in the present study.

o Department of Energy-NEER, "Advanced TRISO Fuels with Zirconium Carbide for Very High Temperature Reactors," 2007 to 2010, two graduate students.

The work is focused on advanced TRISO coated particle fuels. It seeks to develop a thermochemical model and fabricate these advanced fuels for later irradiation testing. This work is distinct from the present GFR work in that it is focused on $\mathrm{UO}_{2}$ kernels with various coatings and intended for a graphite matrix for use in high temperature reactors such as the GenIV, Very High Temperature Reactor (VHTR). 
COST STATUS

\begin{tabular}{|l|r|r|r|r|r|r|}
\hline \multicolumn{1}{|c|}{ Category } & $\begin{array}{c}\text { Approved } \\
\text { Budget } \\
\text { Year 2 } \\
\mathbf{( 2 0 0 6 )}\end{array}$ & $\begin{array}{c}\text { Approved } \\
\text { Budget } \\
\text { Year 2 } \\
\mathbf{2 0 0 7 )}\end{array}$ & $\begin{array}{c}\text { Approved } \\
\text { Budget } \\
\text { Year 3 } \\
\mathbf{( 2 0 0 8 )}\end{array}$ & $\begin{array}{c}\text { No-Cost } \\
\text { Extension } \\
\text { Year 4 } \\
\mathbf{2 0 0 9 )}\end{array}$ & $\begin{array}{c}\text { Total } \\
\text { Budget } \\
\text { Years 1-4 }\end{array}$ & $\begin{array}{c}\text { Actual } \\
\text { Costs to } \\
\text { date }\end{array}$ \\
\hline Salary \& fringe & $\$ 58,721$ & $\$ 60,706$ & $\$ 62,760$ & $\$ 0$ & $\$ 182,187$ & $\$ 201,180$ \\
\hline Equipment & $\$ 22,540$ & $\$ 10,000$ & $\$ 0$ & $\$ 0$ & $\$ 32,540$ & $\$ 33,196$ \\
\hline Travel & $\$ 3,500$ & $\$ 4,000$ & $\$ 4,000$ & $\$ 0$ & $\$ 11,500$ & $\$ 15,119$ \\
\hline $\begin{array}{l}\text { Matrls \& } \\
\text { Supplies }\end{array}$ & $\$ 13,009$ & $\$ 18,455$ & $\$ 22,587$ & $\$ 0$ & & \\
\hline Tuition & $\$ 18,000$ & $\$ 19,000$ & $\$ 20,000$ & $\$ 0$ & $\$ 57,000$ & $\$ 60,288$ \\
\hline Indirect & $\$ 34,230$ & $\$ 37,838$ & $\$ 40,653$ & $\$ 0$ & $\$ 112,721$ & $\$ 112,721$ \\
\hline Total & $\$ 150,000$ & $\$ 150,000$ & $\$ 150,000$ & $\$ 0$ & $\$ 450,000$ & $\$ 450,000$ \\
\hline & & & & & & \\
\hline Cost-share: & & & & & & \\
\hline Undergraduates & $\$ 9,696$ & $\$ 9,696$ & $\$ 10,309$ & $\$ 0$ & $\$ 29,701$ & $\$ 26,390$ \\
\hline Supplies & $\$ 613$ & $\$ 613$ & $\$ 0$ & $\$ 0$ & $\$ 1,226$ & $\$ 2,110$ \\
\hline Indirect & $\$ 4,691$ & $\$ 4,691$ & $\$ 4,691$ & $\$ 0$ & $\$ 14,073$ & $\$ 16,524$ \\
\hline Total & $\$ 15,000$ & $\$ 15,000$ & $\$ 15,000$ & $\$ 0$ & $\$ 45,000$ & $\$ 45,024$ \\
\hline
\end{tabular}

